\title{
Revisiting the morphology of the Cretaceous ommatid beetle Clessidromma palmeri (Coleoptera: Archostemata: Ommatidae)
}

\author{
Yan-Da Li ${ }^{1,3}$ \& Chen-Yang Cai ${ }^{1,2,4}$ \\ 1 Chinese Academy of Sciences, Nanjing Institute of Geology and Palaeontology, Center for Excellence in Life and Paleoenvironment, \\ State Key Laboratory of Palaeobiology and Stratigraphy. Nanjīng, Jiangsu, China. \\ ${ }^{2}$ University of Bristol, School of Earth Sciences. Bristol, United Kingdom. \\ ${ }^{3}$ ORCID: http://orcid.org/0000-0002-9439-202X. E-mail:ydli@pku.edu.cn \\ ${ }^{4}$ ORCID: http://orcid.org/0000-0002-9283-8323. E-mail: cycai@nigpas.ac.cn (corresponding author)
}

\begin{abstract}
The morphology of Clessidromma palmeri Jarzembowski et al. from mid-Cretaceous Burmese amber is revised based on a reexamination of the type specimen. Contrary to previous studies, our observation confirms that Clessidromma has open procoxal cavities. The characters such as platform on the ventral side of head, modified metacoxae, and ridges on head and pronotum are suggested to be diagnostic characters for Clessidromma. Clessidromma zengi Kirejtshuk from the same deposit is transferred into a new genus, as Kirejtomma zengi comb. nov.
\end{abstract}

Keywords. Archostemata; Ommatidae; Clessidromma; Kirejtomma; Burmese amber.

\section{INTRODUCTION}

Archostemata is a small suborder of Coleoptera, represented by only four extant families (excluding Jurodidae; Lawrence, 2016). Many Permian/ Triassic coleopterans (e.g., Permocupedidae, Tshekardocoleidae) were once placed in Archostemata due to their somewhat similar elytral structure (e.g., Ponomarenko, 1969; Kirejtshuk et al., 2014). A recent cladistic analysis, however, suggested that they are indeed stem-group beetles and should not be placed in Archostemata (Beutel et al., 2008). Ommatidae is a small family of Archostemata (McKenna et al., 2019), with three extant genera known to date (Hörnschemeyer \& Beutel, 2016; Escalona et al., 2020). Numerous Mesozoic ommatids have been found across Gondwana and Laurasia (e.g., Ponomarenko, 1969; Tan \& Ren, 2009; Ashman et al., 2015). However, many characters in these compression-impression fossils are either not preserved or hard to interpret. Based on our preliminary examination, the morphological cladistic analysis of Ommatidae by Tan et al. (2012) seems to contain many coding errors, which was probably at least partly caused by the comparatively strong taphonomic artefacts in compression-impression fossils. The recent findings of relatively well-preserved ommatids in mid-Cretaceous Burmese amber have greatly increased our knowledge on the morpho- logical disparity of this family (e.g., Liu et al., 2017; Jarzembowski et al., 2019; Li et al., 2020a, 2021a; Tihelka et al., 2020). The morphological characters of the amber inclusions are less affected by taphonomic artefacts and could be crucial for further phylogenetic studies of Ommatidae.

Jarzembowski et al. (2018) reported a new ommatid species in a new genus, Clessidromma palmeri Jarzembowski et al., from mid-Cretaceous Burmese amber. They mentioned that C. palmeri is unusual in Ommatidae in having tshekardocoleid-like fore legs. However, since the type specimen is strongly carbonized, it is extremely difficult to assess many of the characters of this species under incident light. After a detailed examination under fluorescence, it turns out that many structures were mistakenly illustrated in the original drawings, and some other important features were neglected in the original description by Jarzembowski et al. (2018). The clarified morphology of C. palmeri also permits a re-evaluation of the generic placement of an addition species previously assigned to Clessidromma (Kirejtshuk, 2020).

\section{MATERIAL AND METHODS}

The holotype of Clessidromma palmeri (Figs. 1-5), deposited in the Nanjing Institute of Geology and Paleontology (NIGP), Chinese 
Academy of Sciences, Nanjing, China, was re-examined. The specimen was derived from amber mines near Noije Bum Village $\left(26^{\circ} 20^{\prime} \mathrm{N}, 96^{\circ} 36^{\prime} \mathrm{E}\right)$, Hukawng Valley, Kachin State, northern Myanmar (Jarzembowski et al., 2018).

Photographs under incident light were taken with a Zeiss Discovery V20 stereo microscope. Widefield fluorescence images were captured with a Zeiss Axio Imager 2 light microscope or a Zeiss Lumar V12 stereo microscope combined with a fluorescence imaging system. In some cases, the amber piece was immersed in mineral oil (CAS 8020-83-5) to reduce refraction (Fu et al., 2021). Confocal images were obtained with a Zeiss LSM710 confocal laser scanning microscope, using $488 \mathrm{~nm}$ Argon laser excitation line. Images under incident light and widefield fluorescence were stacked in Helicon Focus 7.0.2 or Zerene Stacker 1.04. Confocal images were stacked in Helicon
Focus 7.0.2. Images were further processed in Adobe Photoshop CC to enhance contrast.

RESULTS

\section{Systematic Paleontology}

Order Coleoptera Linnaeus, 1758

Suborder Archostemata Kolbe, 1908

Family Ommatidae Sharp \& Muir, 1912

Genus Clessidromma Jarzembowski, Wang \& Zheng, 2017

Type species: Clessidromma palmeri Jarzembowski et al., 2017.
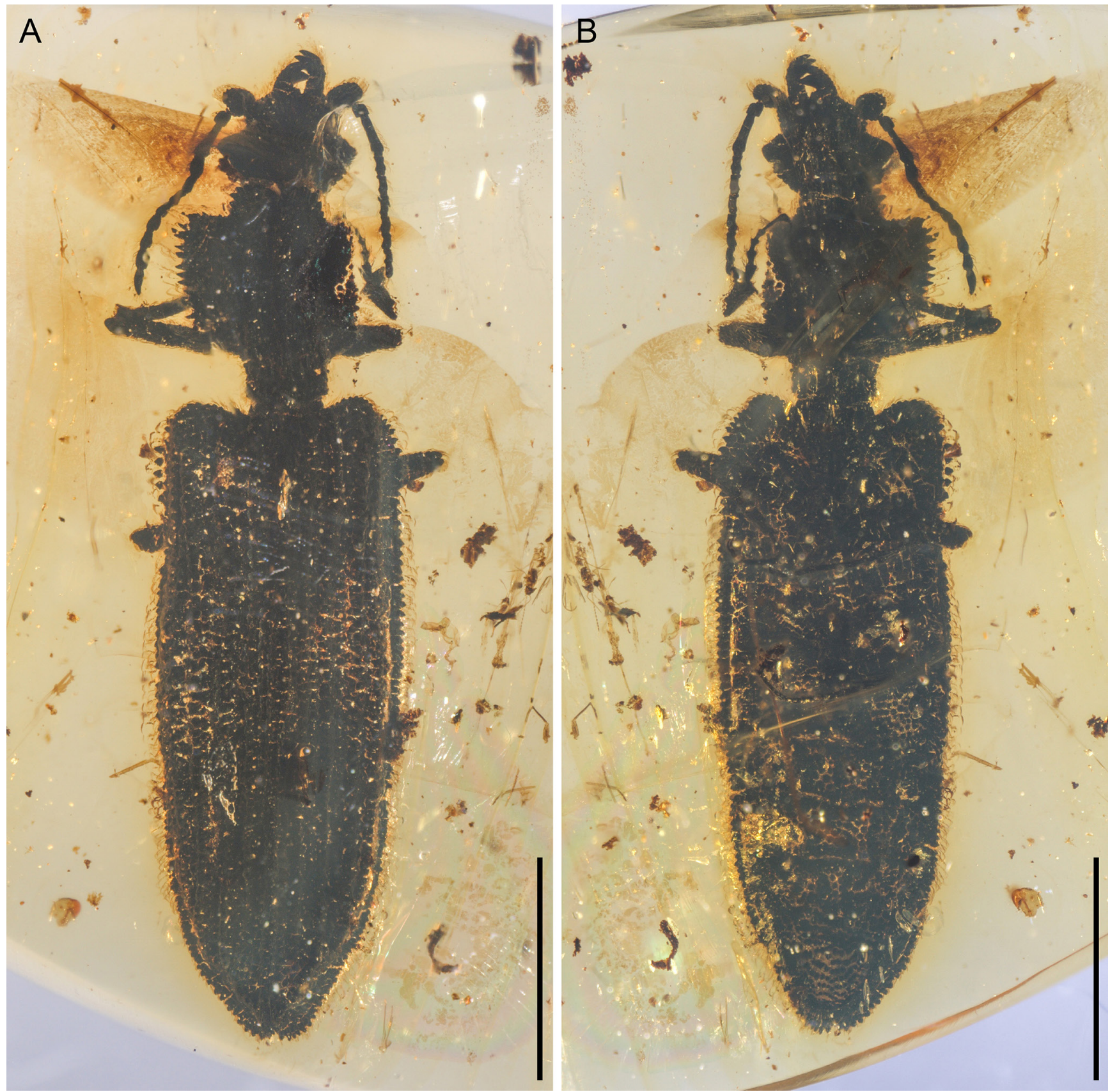

Figure 1. General habitus of Clessidromma palmeri, holotype, NIGP166270, under incident light. (A) Dorsal view. (B) Ventral view. Scale bars: $2 \mathrm{~mm}$. 


\section{Composition: Only Clessidromma palmeri.}

Revised diagnosis: Head roughly hexagonal; dorsal surface with a transverse carina separating vertex and frons; medial portion of ventral surface forming a distinctly elevated platform. Pronotal disc with three longitudinal ridges; lateral edges dentate. Pro- and mesocoxae oblong. Metacoxae with a longitudinal carina medially.

Remarks: Kirejtshuk (2020) merged the genus Lepidomma into Clessidromma. However, Lepidomma actually differs distinctly from Clessidromma (Li et al., 2020b). In C. palmeri, the medial portion of the ventral surface of the head forms a distinctly elevated platform, extending to the posterior end of the neck (Fig. 4A). This elevated platform is unknown in any other ommatids, and could be regarded as a diagnostic character of the genus. Such a structure is obviously absent in Lepidomma (fig. 6A in Li et al., 2020b). The metacoxa of C. palmeri is somewhat aberrant (Figs. 4D, 5F). Though the exact structure of the metacoxa is hard to determine due to the poor preservation of the specimen, it surely lacks the posterior excavation for reception of metafemur, and therefore differs from most other ommatids and cupedids, including Lepidomma. Lepidomma is characterized by a special type of scales with distinctive ridges running down the sides (fig. 4D in Li et al., 2020b), which is absent in C. palmeri. Besides, there are three longitudinal ridges on the pronotal disc of C. palmeri (Fig. 3B), while no such ridges are present in Lepidomma (fig. $4 \mathrm{C}$ in Li et al., 2020b).

\section{Clessidromma palmeri Jarzembowski, Wang \& Zheng, 2017}

(Figs. 1-5)

Material examined: Holotype, NIGP166270, strongly carbonized and crazed, with right portion of prothorax partly polished away. The network of cracks makes it sometimes difficult to determine the real boundaries of sclerites.

Redescription: Body slender and elongate, about $8.6 \mathrm{~mm}$ long and $2.2 \mathrm{~mm}$ wide, tuberculate, with thin setae and scales.
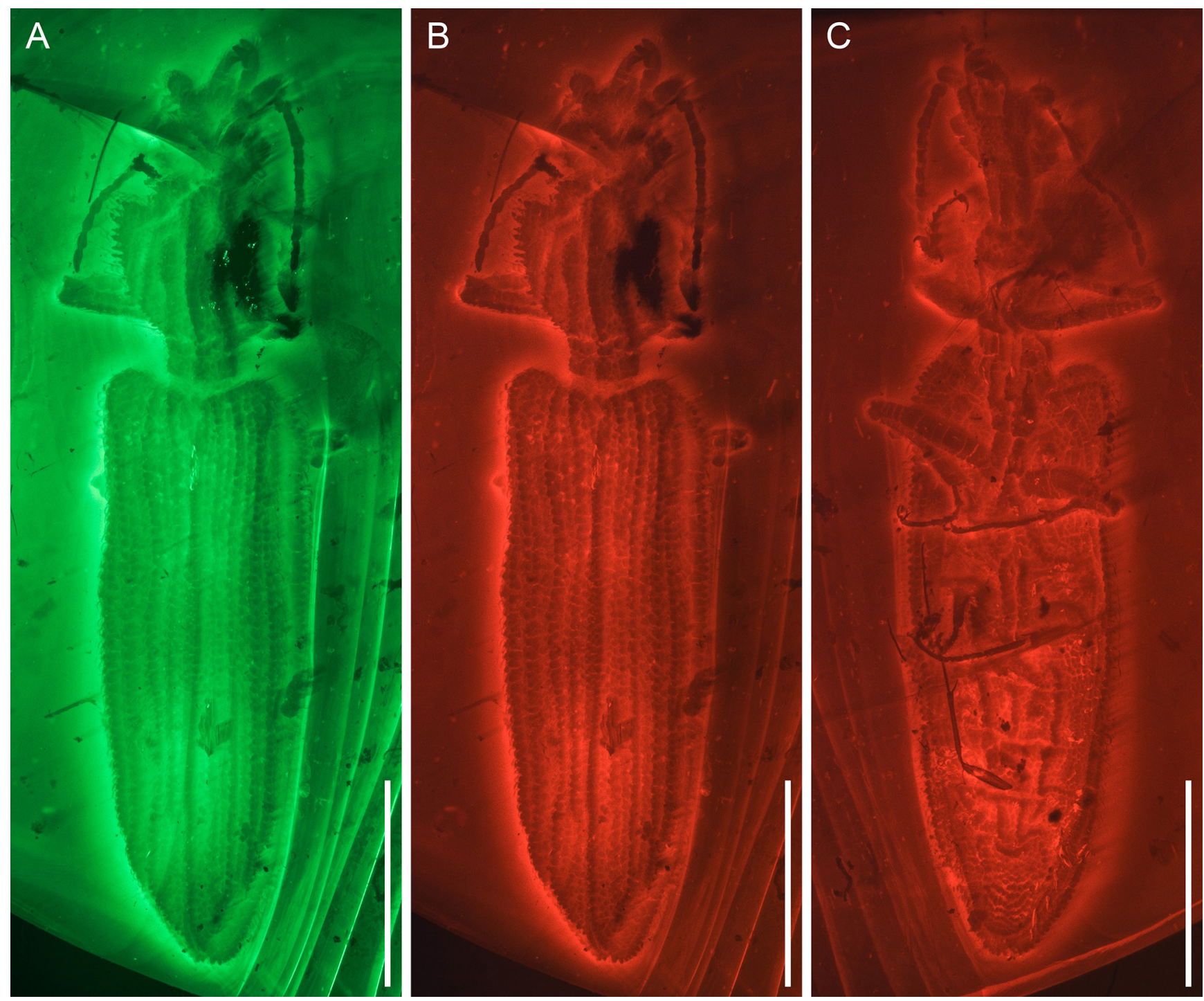

Figure 2. General habitus of Clessidromma palmeri, holotype, NIGP166270, under widefield fluorescence. (A, B) Dorsal view. (C) Ventral view. Scale bars: 2 mm. 
Head (Figs. 3A, 4A) prognathous, roughly hexagonal, constricted posteriorly to form a neck. Vertex and frons separated by a somewhat $\mathrm{v}$-shaped transverse carina. Ventral surface of head forming a distinctly elevated platform medially, extending to posterior end of neck (Figs. 4A, 5A). Compound eyes entire and finely facetted, without interfacetal setae. Antennal insertion area located anteriorly, anteromesad anterior margin of compound eyes, separated by more than two but less than three diameters of antennomere 1. Antennae (Figs. 3A, B, 4A) 11-segmented, fili-moniliform, with thin setae on all segments, extending beyond anterior prothoracic margin, but not reaching posterior prothoracic margin; antennomere 3 about twice as long as 4. Mandibles (Fig. 5A) long, with three vertically aligned teeth. Maxillary and labial palps seemingly short (Fig. 5A). Posteromedian pit on prementum not observed. Separate mentum probably absent.

Pronotal disc (Fig. 3B) gradually narrowed posteriorly, abruptly constricted behind procoxae; anterior extension forming a collar-like, centrally notched neck shield; lateral edges serrate. Notopleural sutures not observed (Fig. 5B). Prosternum (Fig. 4B) comparatively small; lateral edges slightly arcuate; prosternal process short and narrow, not reaching middle region of procoxae. Procoxal cavities contiguous, posteriorly open (Figs. 4B, 5B). Procoxae oblong (Fig. 5B).

Scutellum relatively narrow (Fig. 5I). Elytra elongate (Figs. 2A, B), about 2.5 times as long as wide combined, with distinct longitudinal ridges (primary veins) and rows of maculated window punctures (Fig. 5I); humeri prominent (Fig. 3C); lateral edges serrate; explanate epipleura absent. Mesoventrite (Fig. 5C) long and narrow, with median discrimen, anteriorly with deep procoxal rests. Mesocoxae oblong (Fig. 5C). Metaventrite trapezoidal (Fig. 4D), possibly with an inverted Y-shaped ridge extending from anterior metaventral process to posterior corners. Metacoxae (Figs. 4D, 5F) with a longitudinal carina medially (? or simply oblong with no lateral extension, i.e., somewhat similar to Miniomma Li et al., 2020a).

Legs slender. Femora stout. Tibiae thinner, with well-developed tibial spurs (Figs. 5B, D-F). Tarsi five-seg-
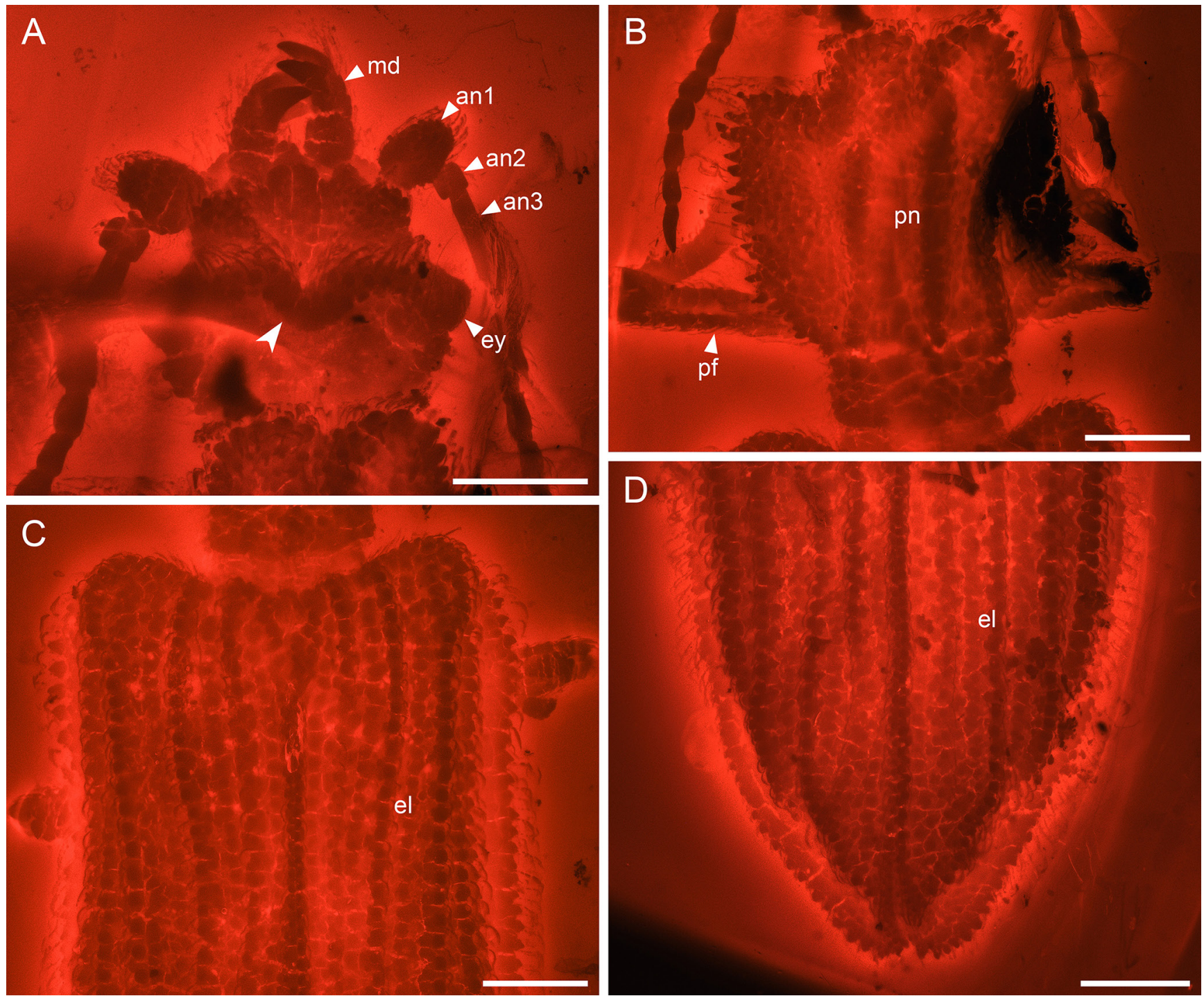

Figure 3. Details of Clessidromma palmeri, holotype, NIGP166270, under widefield fluorescence, dorsal view. (A) Head, showing the v-shaped transverse carina separating vertex and frons (arrowhead). (B) Prothorax. (C) Elytral base. (D) Elytral apex. Abbreviations: an1-3 = antennomeres 1-3; el = elytron; ey = compound eye; $\mathrm{md}=$ mandible; $\mathrm{pf}=$ profemur. Scale bars: $500 \mu \mathrm{m}$. 
mented; tarsomeres simple, not bilobed. Pretarsal claws simple.

Abdomen (Figs. 4D, E) elongate, with five coplanar ventrites, separated by distinct grooves; ventrites 1-4 seemingly with a pair of longitudinal ridges (Fig. 5G; possibly being a taphonomic artefact); anterior margin of ventrite 5 seemingly emarginate (possibly being a taphonomic artefact).
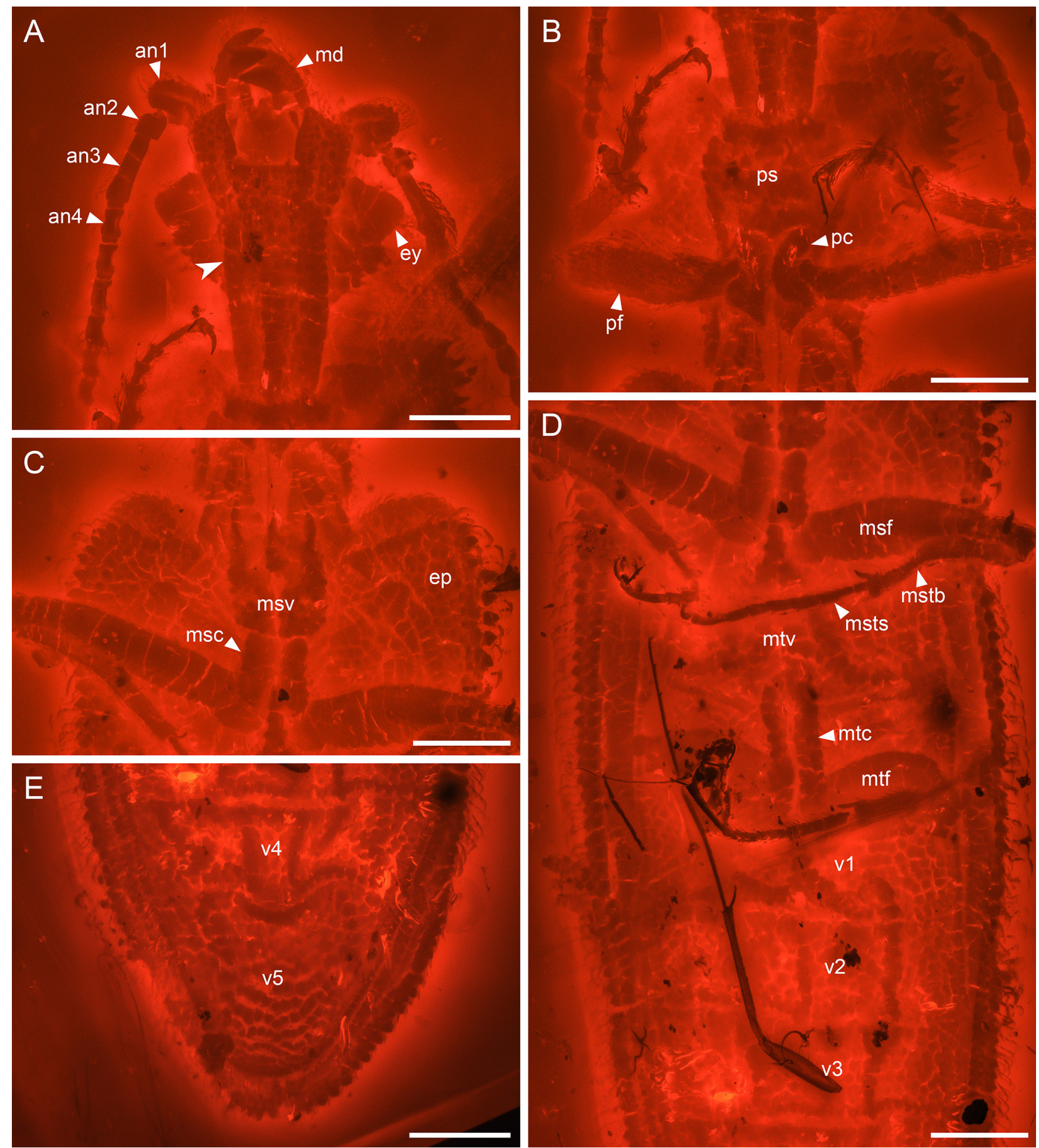

Figure 4. Details of Clessidromma palmeri, holotype, NIGP166270, under widefield fluorescence, ventral view. (A) Head, with arrowhead showing the elevated platform. (B) Prothorax. (C) Mesothorax. (D) Metathorax and abdominal base. (E) Abdominal apex. Abbreviations: an1-4 = antennomeres 1-4; ep = epipleuron; ey = compound eye; $\mathrm{md}=$ mandible; $\mathrm{msc}=$ mesocoxa; $\mathrm{msf}=$ mesofemur; $\mathrm{mstb}=$ mesotibia; $\mathrm{msts}=$ mesotarsus; $\mathrm{msv}=$ mesoventrite; $\mathrm{mtc}=\mathrm{metacoxa} ; \mathrm{mtf}=$ metafemur; $m t v=$ metaventrite; $p c=$ procoxa; $p f=$ profemur; $p s=$ prosternum; $v 1-5=$ ventrites $1-5$. Scale bars: $500 \mu \mathrm{m}$. 
anterior margin (not waveform). Pronotal disc expanding anteriorly; longitudinal ridges absent; lateral edges smooth. Pro- and mesocoxae subglobular. Metacoxae unmodified, with posterior excavations for reception of metafemora. Elytra without prominent longitudinal ridges (primary veins); explanate epipleura absent.

Remarks: Kirejtshuk (2020) reported a new species, Clessidromma zengi Kirejtshuk, from Burmese amber, and assigned it to genus Clessidromma. Clessidromma zengi, however, differs dramatically from C. palmeri, the type species of Clessidromma, and therefore is not a true member of Clessidromma. The head of C. zengi does not possess an elevated platform on the ventral side (fig. 9C in Kirejtshuk, 2020), and its pronotum and elytra lack any distinct longitudinal ridges (figs. 9D, 10A in Kirejtshuk, 2020). Clessidromma zengi has typical metacoxae for ommatid and cupedid archostematans (fig. 10D in Kirejtshuk, 2020). In addition, the lateral pronotal edges are dentate in C. palmeri (Fig. 3B), while they are relatively smooth in C. zengi. The pronotum of $C$. zengi is somewhat more similar to Lepidomma. However, it differs
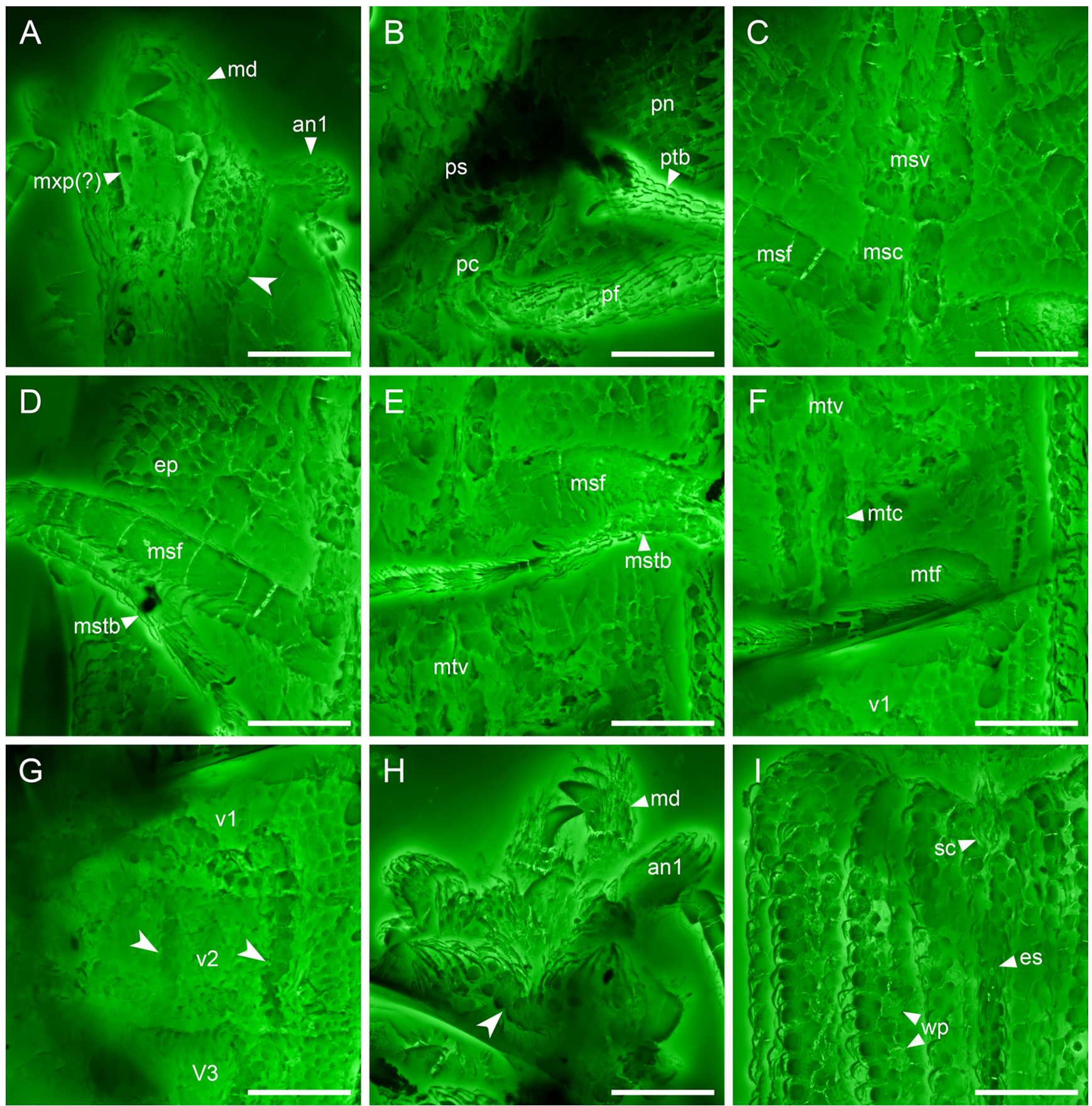

Figure 5. Details of Clessidromma palmeri, holotype, NIGP166270, under confocal microscopy. (A) Head, ventral view, with arrowhead showing the elevated platform. (B) Prothorax, ventral view. (C) Mesothorax, ventral view. (D) Mid leg and elytral epipleuron, ventral view. (E) Mid leg and metathorax, ventral view. (F) Hind leg, ventral view. (G) Abdomen, ventral view, with arrowheads showing the longitudinal ridges (? taphonomic artefact). (H) Head, dorsal view, showing the v-shaped transverse carina (arrowhead). (I) Elytral base, dorsal view. Abbreviations: an $1=$ antennomere 1 ; $\mathrm{ep}=$ epipleuron; $\mathrm{es}=\mathrm{elytral}$ suture; $\mathrm{md}=\mathrm{mandible;} \mathrm{msc}=\mathrm{mes} 0$ -

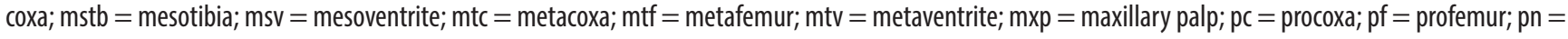
pronotum; $\mathrm{ps}=$ prosternum; $\mathrm{ptb}=$ protibia; $\mathrm{sc}=$ scutellum; $\mathrm{v1}-3=$ ventrite $1-3 ; \mathrm{wp}=$ window punctures. Scale bars: $400 \mu \mathrm{m}$. 
from Lepidomma in lacking the ridged scales and elytral carinae. The character combination of $C$. zengi does not fit into any other known ommatid genera as well. Thus we establish a new genus here to accommodate $C$. zengi. Thus $C$. zengi is here transferred into the new genus as Kirejtomma zengi comb. nov.

Etymology: The generic name is formed based on the generic name "Omma" and the surname of the Russian entomologist Alexander G. Kirejtshuk. The name is neuter in gender.

\section{DISCUSSION}

Jarzembowski et al. (2018) placed Clessidromma in a newly established tribe, Clessidrommatini, mainly based on its prothoracic structures. According to Jarzembowski et al. (2018), the foreleg insertion of Clessidromma is similar to tshekardocoleids, where the insertions are near the middle of the prothorax. Escalona et al. (2020) further explicitly stated that Clessidromma has externally closed procoxal cavities. However, a detailed examination reveals that the prothoracic structure of Clessidromma is actually similar to other ommatids, rather than tshekardocoleids. The procoxal cavities of tshekardocoleids are externally closed and indeed located well away from the posterior edge of prothorax (fig. 29 in Ponomarenko, 1969), whereas the mesoventrite of Clessidromma possesses well-developed procoxal rests (Fig. 4C), indicating that its procoxal cavities are in fact externally open. Besides, in Tshekardocoleidae, the procoxae are widely separated by the broad prosternal process, and the prosternal process extends far beyond the posterior end of procoxae. By contrast, Clessidromma has adjacent procoxae, and its prosternal process is reduced (Fig. 4B), which is typical in Ommatidae (Hörnschemeyer \& Beutel, 2016).

Clessidromma superficially resembles Tetraphalerus Waterhouse in having a rather elongate body shape. The sharp edge of the ventral platform on head may possibly indicate the presence of a Tetraphalerus-like ventrolateral antennal groove. Clessidromma is additionally similar to Tetraphalerus in having longitudinal ridges on pronotum. However, Tetraphalerus is unique in Ommatidae (and differs from Clessidromma) in having antennomeres 5-11 without setae and mushroom-shaped tubercles (Beutel et al., 2008). The separate mentum present in Tetraphalerus and related fossils (Li et al., 2021b) is also not observed in Clessidromma. Considering the high morphological diversity found in fossil Ommatidae, the similarity between Clessidromma and Tetraphalerus might be merely homoplasious. The exact position of Clessidromma within Ommatidae requires further studies.

\section{DATA AVAILABILITY}

The original confocal data are available in Zenodo repository (http://doi.org/10.5281/zenodo.5214200).

\section{ACKNOWLEDGMENTS}

We are grateful to Rolf $\mathrm{G}$. Beutel in providing the micro-CT data of Tetraphalerus for comparison, Rong Huang for technical help in confocal imaging, and Dao-Jun Yuan for help in inspecting the holotype of Clessidromma palmeri deposited at NIGP. Financial support was provided by the Second Tibetan Plateau Scientific Expedition and Research project (2019QZKK0706), the Strategic Priority Research Program of the Chinese Academy of Sciences (XDB26000000 and XDB18000000), and the National Natural Science Foundation of China (41688103).

\section{AUTHORS' CONTRIBUTIONS}

Y.-D.L. and C.-Y.C. conceived the study. Y.-D.L. acquired and processed the photomicrographs. Y.-D.L. drafted the manuscript, to which C.-Y.C. contributed. Both authors gave final approval for publication.

\section{REFERENCES}

Ashman, L.G.; Oberprieler, R.G. \& Ślipiński, A. 2015. Rhopalomma stefaniae gen. et sp. n., the first ommatid beetle from the Upper Jurassic in Australia (Coleoptera: Archostemata: Ommatidae). Zootaxa, 3980: 136-142. D0I

Beutel, R.G.; Ge, S.-Q. \& Hörnschemeyer, T. 2008. On the head morphology of Tetraphalerus, the phylogeny of Archostemata and the basal branching events in Coleoptera. Cladistics, 24(3): 270-298. DOI

Escalona, H.E.; Lawrence, J.F. \& Ślipiński, A. 2020. The extant species of the genus Omma Newman and description of Beutelius gen. nov. (Coleoptera: Archostemata: Ommatidae: Ommatinae). Zootaxa, 4728: 547-574. D0I

Fu, Y.-Z.; Li, Y.-D.; Su, Y.-T.; Cai, C.-Y. \& Huang, D.-Y. 2021. Application of confocal laser scanning microscopy to the study of amber bioinclusions. Palaeoentomology, 4: 266-278. D01

Hörnschemeyer, T. \& Beutel, R.G. 2016. Ommatidae Sharp \& Muir, 1912. In: Beutel, R.G. \& Leschen, R.A.B. (Eds.). Handbook of Zoology, Arthropoda: Insecta, Coleoptera, beetles, Vol. 1: morphology and systematics (Archostemata, Adephaga, Myxophaga, Polyphaga partim). 2. ed. Berlin, Walter de Gruyter. p. 52-56. D0I

Jarzembowski, E.A.; Wang, B. \& Zheng, D. 2018. A slender new archaic beetle in Burmese amber (Coleoptera: Archostemata). Alcheringa, 42(1): 110-114. DOI

Jarzembowski, E.A.; Wang, B. \& Zheng, D. 2019. A new scaly archaic beetle (Coleoptera: Archostemata) from mid-Cretaceous Burmese amber. Cretaceous Research, 99: 315-320. DOI

Kirejtshuk, A.G. 2020. Taxonomic review of fossil coleopterous families (Insecta, Coleoptera). Suborder Archostemata: superfamilies Coleopseoidea and Cupedoidea. Geosciences, 10: 73. DOI

Kirejtshuk, A.G.; Poschmann; M., Prokop, J.; Garrouste, R. \& Nel, A. 2014. Evolution of the elytral venation and structural adaptations in the oldest Palaeozoic beetles (Insecta: Coleoptera: Tshekardocoleidae). Journal of Systematic Palaeontology, 12(5): 575-600. D0I

Lawrence, J.F. 2016. Classification (families \& subfamilies). In: Beutel, R.G. \& Leschen, R.A.B. (Eds.). Handbook of Zoology, Arthropoda: Insecta, Coleoptera, beetles, Vol. 1: morphology and systematics (Archostemata, Adephaga, Myxophaga, Polyphaga partim). 2. ed. Berlin, Walter de Gruyter. p. 13-22. DOI 
Li,Y.-D.;Yamamoto, S.; Huang, D.-Y.\& \& Cai, C.-Y. 2020a. A miniaturized ommatid beetle in mid-Cretaceous Burmese amber (Coleoptera: Archostemata: Ommatidae). Papéis Avulsos de Zoologia, 60: e20206063. D01

Li, Y.-D.; Tihelka, E.; Yamamoto, S.; Huang, D.-Y. \& Cai, C.-Y. 2020b. A close affinity of the enigmatic genus Stegocoleus with Lepidomma revealed by new fossil evidence (Coleoptera: Archostemata: Ommatidae). Palaeoentomology, 3(6): 632-640. D01

Li, Y.-D.; Yamamoto, S.; Huang, D.-Y. \& Cai, C.-Y. 2021a. New species of Paraodontomma from mid-Cretaceous Burmese amber with muscle tissue preservation (Coleoptera: Archostemata: Ommatidae). Papéis Avulsos de Zoologia, 61: e20206153. D0I

Li, Y.-D.; Huang, D.-Y. \& Cai, C.-Y. 2021b. Revisiting the morphology and systematic placement of the enigmatic Cretaceous ommatid beetle Bukhkalius lindae (Coleoptera: Archostemata: Ommatidae). Papéis Avulsos de Zoologia, 61: e20216128. DOI

Liu, Z.; Tan, J.; Slipinski, A.; Jarzembowski, E.A.; Wang, B.; Ren, D. \& Pang, H. 2017. Brochocoleus zhiyuani, a new species of brochocolein beetle (Coleoptera: Ommatidae) from the Cretaceous amber of Myanmar. Annales Zoologici, 67: 79-85. D0I
McKenna, D.D.; Shin, S.; Ahrens, D.; Balke, M.; Beza-Beza, C.; Clarke, D.J.; Donath, A.; Escalona, H.E.; Friedrich, F.; Letsch, H.; Liu, S.; Maddison, D.; Mayer, C.; Misof, B., Murin, P.J.; Niehuis, 0.; Peters, R.S.; Podsiadlowski, L.; Pohl, H.; Scully, E.D.; Yan, E.V.; Zhou, X.; Ślipiński, A. \& Beutel, R.G. 2019. The evolution and genomic basis of beetle diversity. Proceedings of the National Academy of Sciences, USA, 116(49): 24729-24737. DOI

Ponomarenko, A.G. 1969. Historical development of archostematan beetles. Trudy Paleontologicheskogo Instituta, 125: 1-240. [In Russian]

Tan, J. \& Ren, D. 2009. Mesozoic archostematan fauna from China. Beijing, Science Press. [In Chinese with English summary]

Tan, J.; Wang, Y.; Ren, D. \& Yang, X. 2012. New fossil species of ommatids (Coleoptera: Archostemata) from the Middle Mesozoic of China illuminating the phylogeny of Ommatidae. BMC Evolutionary Biology, 12: 113. DOl

Tihelka, E.; Huang, D. \& Cai, C. 2020. New data on Ommatidae (Coleoptera) from mid-Cretaceous Burmese amber. Cretaceous Research, 106: 104253. DOI 